\title{
La capoeira como herramienta de inclusión social e innovación educativa: Una propuesta para la asignatura de Educación Física
}

\author{
Capoeira as a tool of social inclusion and educational innovation: \\ A proposal for Physical Education at school

\begin{abstract}
A capoeira como ferramenta de inclusão social e inovação educativa: Uma proposta na matéria de Educação Física
\end{abstract}

\author{
Evelyn Ríos Valdés
}

Teléfono: (34) 656491758. Correo electrónico: eriosvaldes@yahoo.es

\begin{abstract}
RESUMEN
El presente artículo se elabora en base al resultado del trabajo final de Máster de Actividad Motriz, Educación e Intervención Social, realizado en la Universidad de Barcelona. Se pretende discutir la importancia de la capoeira como un instrumento pedagógico de inclusión social en el ámbito escolar, específicamente a través de la asignatura de Educación física. Para esto se revisaron los antecedentes bibliográficos y se creó una unidad didáctica de capoeira para aplicar en los cursos de primaria de la Escuela General Prim de Barcelona, lugar donde se realizó una práctica profesional de 100 horas. En la planificación de la unidad didáctica, se estableció como objetivo trabajar dos contenidos específicos, seleccionados desde el currículo de educación física de Cataluña: la creatividad y la expresión. Finalmente, se analizaron los resultados de estas prácticas y se elaboró un proyecto de innovación docente, que consiste en una progresión metodológica de capoeira.
\end{abstract}

Palabras clave: capoeira, innovación educativa, inclusión social, expresión, creatividad, educación física.

\section{ABSTRACT}

This article is written as a result of the final project in the Masters of Motor Activity and Education at University of Barcelona. The aim of this work is to discuss the importance of capoeira as a pedagogical tool for social inclusion at school, specifically in the subject of Physical Education. Precedent bibliography has been reviewed to create a teaching unit for the professional practice of 100 hours at General Prim School in Barcelona. While planning the teaching unit, the goal was to focus in two specific subjects, the choice of the subjects was done taking into account the Physical Education Planning in Catalunya, the subjects chosen are creativity and physical expression. At the end of a deep analysis of the results registered in the time spent with the kids, I created a project of teaching innovation based on a methodological progression of capoeira.

Key words: capoeira, educational innovation, social inclusion, expression, creativity, physical education.

\section{RESUMO}

Elaborado com base no resultado do trabalho final de Mestrado de Atividade Motriz, Educação e Intervenção Social, realizado na Universidade de Barcelona. Pretende-se discutir a importância da capoeira como um instrumento pedagógico de inclusão social no âmbito escolar, especificamente por meio do conteúdo da Educação Física. Para isso, revisaram-se os antecedentes bibliográficos e criou-se uma unidade didática da capoeira para aplicar nos cursos de primária na "Escola General Prim", de Barcelona, lugar onde se realizou uma prática profissional de 100 horas. Na planificação da unidade didática, estabeleceu-se como objetivo trabalhar dois conteúdos específicos selecionados desde o currículo de Educação Física da Catalunha: a criatividade e a expressão. Finalmente, analisaram-se os resultados de estas práticas e elaborou-se um projeto de inovação docente, o qual consiste em uma progressão metodológica de capoeira.

Palavras chave: capoeira, inovação educativa, inclusão social, expressão, criatividade, educação física. 


\section{INTRODUCCIÓN}

En este trabajo se plantea una propuesta educativa y social a través de las artes corporales, específicamente la capoeira y su integración a la escuela en su rol socializador.

Las artes corporales, como la capoeira, tratan de permitir una transformación individual de la vida de las personas dentro de un colectivo. Este enfoque integrador del individuo dentro del colectivo se ejecuta agrupando herramientas de prevención para la salud de las personas; tales como conocimientos, valores y hábitos para el cuidado de la corporalidad, conocimiento personal y autoestima. Aspectos que deben ser aprendidos primeramente desde la familia, pero también deben ser fuertemente trabajados en la escuela, sobre todo en centros inmersos en contextos de riesgo social, donde la mayoría de las familias de la escuela son monoparentales, con problemas económicos, con carencias emocionales, sociales y culturales.

Uno de los objetivos de la propuesta capoeira y Educación física busca recuperar la autoestima de niños y jóvenes marginados; esto se trabaja a través de la disciplina, esfuerzo y tiempo que se debe invertir con amor, entrega y dedicación en las prácticas, para conseguir las metas propuestas como grupo. Así como también la práctica del arte para el cambio social fomenta la organización social, el liderazgo y el trabajo colectivo.

(...) Los hechos artísticos por lo tanto, son transformadores de las formas de interpretar el mundo y esto es lo que posibilita que sus protagonistas se transformen, a su vez, en creadores de nuevas realidades en sus propios espacios comunitarios (Olaechea \& Georg, 2007, p. 61).

La capoeira es una actividad de gran riqueza dentro del área de Educación física. Es posible desarrollar habilidades de una manera original y con el soporte musical, dando sentido a la interdisciplinariedad educativa. De la misma manera, forman parte de esta modalidad la expresión corporal, el sentido del ritmo y la educación para la paz. Además, la educación a través de la capoeira puede formar o cambiar las actitudes de los individuos (Mello, 2010).

De Oliveira \& Heine (2008) señalan que el proceso de interacción entre la capoeira y la escuela parece ser irreversible y viene aumentando expresivamente en los últimos años, y recuerdan que cabe a los profesores reconocer esta realidad y establecer un contacto más significativo con la modalidad, explorando todo su potencial educativo. Así, la capoeira pasará a ser vista y vivida como un poderoso instrumento en el proceso educativo, interfiriendo en la vida de la escuela e influenciando positivamente su cotidiano.

En sus orígenes históricos, la práctica de la capoeira era una forma de lucha de liberación del esclavo negro en Brasil, pero por varios motivos como la represión policial, los prejuicios sociales, así como la necesidad de protegerla como expresión artística, hicieron que finalmente se tornara como un juego entre camaradas. Hoy en día, después de tantas batallas por su otorgarle su valor, la capoeira es reconocida como deporte nacional en Brasil y se practica en mas de 120 países en todo el mundo, sin límites de idioma y cultura.

El 26 de Noviembre de 2014 la capoeira fue reconocida como Patrimonio Cultural Inmaterial de la Humanidad por la UNESCO. La intención de las múltiples asociaciones de capoeira en el mundo es integrarla como una herramienta multicultural de inclusión social. Otra buena noticia para los educadores de este arte es que el pasado 19 de Mayo la Comisión de Educación, Cultura y Deporte de Brasil aprobó el proyecto de ley que 
reconoce el carácter educativo y formativo de la capoeira y autoriza a las escuela públicas y privadas de educación básica para entrar en alianza con las organizaciones que agrupan a maestros y profesionales de capoeira para enseñar a sus alumnos respecto a esta práctica deportiva y cultural.

A través de la revisión bibliográfica de diferentes autores, comenzamos definiendo la capoeira desde la perspectiva de la corporalidad. Luego, con el objetivo de dar al lector una idea más clara de lo que es capoeira, se detallan los aspectos de la lógica interna en relación a los compañeros, tiempo, espacio, símbolos y estrategia, así como la importancia del componente de la musicalidad.

Más adelante, abordamos la capoeira como herramienta educativa y de inclusión social, desde las experiencias de varios autores que afirman esta característica desde la escuela y proyectos sociales. A continuación se relaciona la capoeira con el currículo de Educación física, específicamente a través del aprendizaje de la creatividad y la expresión, que consideramos son habilidades importantes de aprender para la autoestima de los alumnos, de frente a la inclusión social.

Se contextualiza la escuela donde se llevó a cabo la práctica de capoeira en la clase de Educación física y analizan los resultados de las sesiones. A partir de este trabajo planifica un proyecto de innovación docente, para aplicar en el sector de Educación física, se da énfasis a la progresión metodológica de aprendizaje de la capoeira en los cursos de primaria.

\section{OBJETIVOS}

Los objetivos planteados para el proceso de la elaboración del tema son los siguientes:

- Definir la capoeira y explicar factores que determinan el juego.

- Analizar la capoeira como herramienta de inclusión social.

- Incluir la capoeira como contenido del currículo de Educación física.

- Analizar la unidad didáctica de capoeira en la clase de Educación física en la Escuela General Prim.

- Estructurar una propuesta de innovación docente de una secuencia metodológica desde primer ciclo hasta tercer ciclo de primaria para la Escuela General Prim.

\section{MARCO TEÓRICO}

\subsection{LA CORPOREIDAD Y LA CAPOEIRA}

Zubiri (1986) hace referencia a un concepto que denomina momento de corporeidad. Este momento es el estar presente en la realidad física. Es nuestra propia existencia, nuestra vida. Define la corporeidad como la vivencia del hacer, sentir, pensar y querer; el ser humano es y se vive solo a través de su corporeidad. Esto es la corporeidad humana, pienso y siento al tiempo que hago; actúo porque pienso y siento.

Es por la corporeidad que el hombre dice que es de carne y hueso. Ella es el testimonio carnal de nuestra existencia. La corporeidad integra todo lo que el hombre es y que puede manifestar 
en este mundo: espíritu, alma, sangre, huesos, nervios, cerebro, etc. La corporeidad es más de que sólo un hombre; es cada uno en todos los otros (Freire, 1991, Cit. en Tavares, 2006, p 63).

La corporeidad trasciende de la esencia material del cuerpo, va más allá y se constituye en un cuerpo extendido y prolongado en los objetos y las personas en las que uno imprime su identidad. Corporeidad soy yo y todo lo que me identifica, todo aquello en lo que dejamos huella; en lo que nos corporizamos aun no estando de cuerpo presente, como la letra, frases distintivas, gestos personales, hábitos característicos, ropa particular, pertenencias representativas, todos componentes por los que se reconoce la identidad de una persona (Grasso, 2006).

En este contexto, el concepto de corporeidad puede ser extremadamente relevante para comprender la capoeira y el universo de representaciones humanas que abarca, esto es, su riqueza cognitiva por lo que estimula en el ser humano todos los sentidos: musicalidad, baile, juego y filosofía de vida en un ritual colectivo.

Para Tavares (2006) la capoeira hoy en día se presenta como una posibilidad de ejercicio lúdico, de expresión humana, de acción por placer, de danza, de música, de diversión, de improvisación, de ritmo y fiesta. Por esta razón se hace necesario rescatar la cultura y la historia de la capoeira para que podamos comprender el cuerpo y sus transformaciones socioculturales.

Acción o conducta motricia es una acción con sentido, es decir con intencionalidad para la superación. No se trata de un mero movimiento de desplazamiento de un cuerpo en el espacio ni de las prácticas repetitivas de un gesto, sino que acción es la práctica creadora y constructora de sentido, de intencionalidad e identidad. Puedo decir que movimiento se limita en el ser humano a todo gesto reflejo o involuntario, por ejemplo los movimientos del sistema digestivo, el pestañar, el bostezar, los calambres, etc. Entonces la motricidad está en todas las acciones que tienen una significancia para el individuo.

Trigo (1999), siguiendo a Sergio (1996), clasifica la conducta motricia de la siguiente manera:

- Ludo motricidad: relacionadas a las acciones lúdicas y de placer.

- Ergo motricidad: acciones relacionadas con el trabajo y rendimiento.

- Ludo-ergo motricidad: una mezcla de acciones que implican placer y rendimiento.

Se suma a esta categorización el concepto de Etno-motricidad, que son las acciones relacionadas a la cultura y tradición propia de una comunidad. Estas acciones otorgan identidad cultural y conexión con la propia historia, generando así una dinámica relacional, simbólica y funcional singular (Gonçalves et al., 2012).

Bajo esta conceptualización de las conductas motricias se pueden clasificar y comprender los aspectos motrices que abarca la práctica de capoeira; cabe dentro de cada una de las clasificaciones por separado y también en todas a la vez. Esta clasificación, llevada al tema de capoeira, va a depender exclusivamente del contexto en que esta es aprendida y de qué manera un individuo la vivencie. Por ejemplo, puede representar un pasatiempo, una forma de recreación, entrenamiento dedicado y de gran esfuerzo. También puede ser una fuente laboral, ya sea trabajo como profesor de capoeira, como también trabajar en shows y presentaciones artístico-culturales. Cabe mencionar que en varias localidades de Brasil, y del mundo, la capoeira es folclore vida, es decir, que es parte del día a día de las personas, en un contexto determinado. 
Tabla 1. Características de la capoeira según clasificación de la motricidad

\begin{tabular}{|c|c|}
\hline Clasificación de motricidad & Capoeira según la motricidad \\
\hline $\begin{array}{l}\text { Ludo-motricidad } \\
\text { Las acciones provenientes de las actividades } \\
\text { que realiza el ser humano sin ningún fin fuera } \\
\text { de ellas mismas. Se relacionan al ocio y no tie- } \\
\text { nen ninguna utilidad, se llevan a cabo por puro } \\
\text { placer, por expresión o por agonismo. Su fin } \\
\text { nace y muere en sí mismo }\end{array}$ & $\begin{array}{l}\text { El juego de capoeira } \\
\text { EI sentido lúdico de la lucha disfrazada en danza } \\
\text { El placer de vivenciar la música, el canto y el rit- } \\
\text { mo de manera ritual y festiva }\end{array}$ \\
\hline $\begin{array}{l}\text { Ergo-motricidad } \\
\text { Acciones relacionadas con el mundo laboral. } \\
\text { Pero no todas las acciones laborales son mo- } \\
\text { tricidad, más bien son solamente aquellas que } \\
\text { permiten a la persona que las realiza ser más } \\
\text { humano y seguir creciendo en su proceso de } \\
\text { humanización. Las acciones del mundo del } \\
\text { trabajo que no cumplan estas características } \\
\text { solamente son movimiento }\end{array}$ & $\begin{array}{l}\text { El entrenamiento de movimientos específicos de } \\
\text { ataque-defensa } \\
\text { Ejercicios de complejidad acrobática como saltos } \\
\text { y destrezas de suelo } \\
\text { Enseñar capoeira como trabajo profesional } \\
\text { Práctica constante en los instrumentos musicales } \\
\text { Aprendizaje del idioma portugués }\end{array}$ \\
\hline $\begin{array}{l}\text { Ludoergo-motricidad } \\
\text { Acciones que están entre lo lúdico y lo } \\
\text { ergonómico. Es decir, son aquellas acciones } \\
\text { que realiza el ser humano que implican placer } \\
\text { y al mismo tiempo eficiencia y rendimiento. Es } \\
\text { el caso del deporte, la danza, el circo, el teatro, } \\
\text { la capoeira. etc. Pero solo constituyen } \\
\text { motricidad cuando la persona que la realiza } \\
\text { está comprometida con la acción y debe } \\
\text { implicar el pensamiento crítico-creativo, la } \\
\text { afectividad y voluntad del sujeto }\end{array}$ & $\begin{array}{l}\text { La aplicación de técnicas de defensa y ataque, } \\
\text { acompañado por destrezas aplicadas al juego de } \\
\text { capoeira, con el estímulo de la música, el ritmo, } \\
\text { táctica y estrategia de juego. Es la mezcla del tra- } \\
\text { bajo eficiente y el placer de jugar }\end{array}$ \\
\hline $\begin{array}{l}\text { Etno-motricidad } \\
\text { Prácticas corporales (juegos, actividades lúdi- } \\
\text { cas, luchas, danzas) con características propias } \\
\text { de un pueblo comunidad, desarrolladas con } \\
\text { intencionalidad y relacionadas a procesos edu- } \\
\text { cativos de tradición y resistencia de tales ma- } \\
\text { nifestaciones }\end{array}$ & $\begin{array}{l}\text { Su origen histórico de los esclavos en busca de } \\
\text { libertad } \\
\text { Represión y persecución } \\
\text { Constante lucha por la justicia social } \\
\text { Su riqueza cultural en rito, tradición, folclore, } \\
\text { músicas tradicionales de dominio popular }\end{array}$ \\
\hline
\end{tabular}

Como se puede relacionar claramente en Tabla 1, la capoeira es una disciplina que abarca todos los aspectos de la motricidad y es una manifestación de la corporalidad desde varios puntos de vista diferentes. Esto va a depender en cómo cada persona vivencie la capoeira y de la forma que esta se contextualice. 


\subsection{LOS COMPONENTES DE LA LÓGICA INTERNA}

El juego de capoeira acontece entre dos jugadores que, no importando su tamaño, edad ni sexo realizan un diálogo corporal continuo y donde cada palabra de este diálogo es a través de movimientos de ataques, defensas, contra-ataques, acrobacias y desplazamientos expresivos al ritmo de la música; entonces, esta lucha de juego y danza se manifiesta dentro de un círculo formado por los restantes jugadores y la orquesta musical. El juego termina cuando uno de los jugadores se detiene y extiende su mano en señal de agradecer y concluir el juego.

Vamos a considerar la lógica interna de una situación motriz, como el sistema de características internas, pertinentes y propias de una actividad determinada (Parlebas, 2001), es decir, es el conjunto de relaciones y acciones de un individuo en la acción motriz y que determinan y diferencian a cada deporte o disciplina corporal.

Según la clasificación de los deportes propuesta por Parlebas (2001), la capoeira es muy complicada de encasillar ya que contiene elementos de una actividad física con oposición, porque se juega uno en frente de otro, pero a la vez puede ser considerado de colaboración, ya que la capoeira solo puede ocurrir gracias a la participación de un colectivo, en donde cada uno cumple un rol determinado en el contexto y tiempos de la roda de capoeira. Entonces, se podría decir que la capoeira es una práctica en que la interacción motriz conjuga la oposición y la cooperación, pero esto se dificulta cuando solo se le da esta connotación a los deportes de duelos entre equipos como el baloncesto, el futbol o el voleibol.

Por otro lado, por las características propias de la capoeira, me atrevería a afirmar que está dentro de las prácticas de expresión motriz, las cuales son consideradas en esencia psicomotrices o socio-motrices cooperativas. Por tanto, se podrá considerar dentro de los grupos de situaciones psicomotrices o socio-motrices colaborativas, por la gran interacción motriz que presenta y una baja incertidumbre del entorno.

Además, las prácticas de expresión socio-motriz colaborativa tienen aspectos dominantes en su lógica interna como la función simbólica y expresiva (Mateu \& Torrents, 2012), estas son características fundamentales también de la capoeira, sin embargo hay quienes afirman que los deportes de oposición, no se pueden considerar como actividades expresivo motrices.

Las disciplinas deportivas de oposición en las que la forma del movimiento es el objeto de la confrontación en un proceso de reglamentación explícito y escrito para todos no pertenecen al campo de las actividades físicas expresivas o artísticas (Tribalat, 2005, Cit. en Mateu \& Torrents, 2012, p. 50).

La capoeira es una lucha, arte, danza, deporte, expresión cultural, teatro, música y poesía. No se puede identificar en una sola categoría, ya que no es ninguna, pero sí es todas a la vez. Considerando este tipo de clasificación de la actividad motriz y el juego por parte de los autores citados, y siendo una experta en esta disciplina, me atrevo a clasificar la capoeira como una expresión de la motricidad de colaboración y oposición.

Considerando la clasificación de los subdominios de las situaciones motrices de expresión artística (Mateu \& Torrents, 2012) se puede establecer que en la capoeira las situaciones motrices son en presencia de colaboración, en presencia de adversario, en ausencia de incertidumbre en el medio de ejecución de la práctica y, por último, en presencia de rasgos rítmicos, expresivo y comunicativos. 


\subsubsection{Los Compañeros}

La comunicación entre los dos capoeristas, cuando están jugando al centro de la roda, viene influida directamente por el ritmo musical que se establece para jugar. En términos generales, existe siempre la intención de fintar los golpes de manera tal de no comunicar el momento real en que van a ser realizado.

El contacto visual es de vital importancia para anticipar los movimientos y para aplicar una respuesta y/o generar nuevas preguntas en el diálogo; al igual que en la danza, no existe el lenguaje oral.

El contacto corporal es parte de la capoeira, específicamente cuando se trabajan técnicas, secuencias coreográficas y acrobacias en las cuales existe apoyo en el cuerpo del compañero. Además, existe contacto físico en la aplicación de movimientos desequilibrantes, aplicados con diferentes partes del cuerpo. Por lo general, en la roda de capoeira existe la comunicación a través de gestos, miradas, movimientos, señas y símbolos. Por ejemplo el maestro o persona responsable, va a dirigir o dar una instrucción a través de un canto que significa algo determinado para la situación.

También en los entrenamientos existen códigos de comunicación entre los participantes del grupo, como un saludo característico de ese grupo, asignación de apodos o nombres de fantasía a los integrantes. Las personas que llevan más tiempo de práctica logran la comunicación verbal a través del idioma Portugués (de Brasil).

\subsubsection{El Espacio de juego}

El espacio de juego, no tiene medidas formales y va a depender de la cantidad de jugadores presentes en la roda. Esta conformación permite concentrar la atención y el sonido en el centro de la roda, facilitando el contacto visual y aislando a la dupla de jugadores del exterior.

La roda de capoeira representa el lugar tradicional y formal en donde se juega capoeira y se interactúa con otros capoeristas. Los jugadores siempre deben permanecer jugando dentro de este círculo, si salen fuera de la roda, ya deja de ser un juego de capoeira, y todo lo que pueda ocurrir fuera de la roda, no corresponde a capoeira.

\subsubsection{El Tiempo}

La roda de capoeira es un ritual que no tiene tiempo de duración oficialmente determinado. Solo se sabe del inicio y del fin porque van ocurriendo acciones, hechos y símbolos que van dando cuenta lo que está sucediendo en la roda. Es como contar una historia narrada con cantos, juego y expresión corporal. Pero lo común es que dure entre una a dos horas cronológicas.

El ritual comienza una vez que están todas las personas involucradas en la actividad, ubicadas en un círculo cerrado. Pueden estar todos de pie o todos sentados, donde se colocan los instrumentos es donde será el inicio y termino de cada juego. Los instrumentos musicales son muy importantes en capoeira, sin música no hay juego.

El comienzo del toque de los instrumentos es la señal de inicio del ritual, luego viene el canto de entrada que es cantado por la persona que está tocando el berimbau medio o gunga. El canto es apoyado por el energético coro de todas las personas en la roda. 
Los jugadores y los músicos con berimbaus, pandeiros y otros instrumentos tradicionales forman un círculo, que encierra a dos jugadores que tienen un juego en el medio. Los nuevos jugadores entran en el círculo al pie del birimbao, cuando un juego está acabado o 'comprar' el juego por intervenir y detener el juego por un momento, luego de comenzar un nuevo juego con la persona el nuevo jugador se enfrenta (De Oliveira \& Heine, 2008, p. 30).

A su vez, las personas que están en el círculo acompañan el canto con un característico juego de batir las palmas y responden el coro del canto. En ese momento, la persona que toca el berimbau invita a dos personas a jugar capoeira. Estas se ubican en una posición hincada bajo el instrumento birimbao, uno en frente del otro y cuando el maestro o profesor da la señal con el birimbao, los dos jugadores entran al centro de la roda a desenvolver su juego. Los juegos tampoco tienen un tiempo de duración determinado. Es el maestro que guía la roda el que determina cuando se acaba un juego para que otros dos entren a jugar.

\subsubsection{Los Símbolos}

En el juego de capoeira existen acciones propias de la disciplina y que dan significados simbólicos a los jugadores y determinan la forma de continuar el juego, a continuación se mencionan los que se consideran más significativos:

- Posición de cuclillas al pie del berimbau: es el símbolo de disposición para comenzar un juego. En esta posición, el capoeristas hace el gesto de pedir bendición y protección antes de entrar a jugar, la petición es dirigida en base a sus creencias personales.

- El saludo de inicio y fin de juego: es un símbolo de camaradería y buena disposición a colaborar en el juego.

- La vuelta al mundo: ocurre cuando uno de los jugadores invita al otro a caminar alrededor de la roda, en momentos de cansancio para calmar alguna situación de peligro, o para preparar una estrategia de juego.

- Las llamadas: son posturas corporales que un jugador realiza en frente de otro y simboliza lo mismo que la vuelta al mundo.

\subsubsection{Estrategia motriz}

Para facilitar la comprensión de lo que es capoeira, es importante considerar un parámetro que permite describir la estructura funcional de un deporte, esto es la estrategia motriz, que es el papel que el jugador debe o puede asumir en el transcurso del juego, se refiere al rol que se desarrolla en cada sistema de juego (Hérnandez, 2008).

En el transcurso de la roda de capoeira, un mismo jugador cumple con diferentes roles motrices, dependiendo del momento; puede ser un jugador activo, jugador observador, cantante, músico y animador. Pero, considerando el momento específico de juego, se puede analizar algunas formas de estrategia que se mencionan a continuación.

El uso de la estrategia o malandragem (término usado en el lenguaje interno de capoeira): está fundamentada en las raíces de este arte. La lucha del más débil contra el más fuerte llevó a los esclavos a utilizar la astucia, las artimañas y la agilidad por sobre la fuerza y el combate frontal.

La estrategia que un capoerista va a utilizar en su juego dependerá de las características que presente el otro jugador, tales como peso, estatura, experiencia, habilidad, etc. Así 
como de las características propias, lo que lo puede llevar a adoptar una posición defensiva basada en desplazamientos de un lado hacia otro de tal manera de no ofrecer un blanco inmóvil para los ataques que vienen, esperando el momento oportuno para lanzar un contraataque.

También es muy ocupada en la etapa inicial la estrategia de unirse a la energía del movimiento del otro, generando continuidad de juego, facilitando el diálogo con el compañero, creando secuencias y coreografías, demostrando habilidades, destrezas y formas de expresión corporal.

Una estrategia ocupada habitualmente por los jugadores más avanzados es la de utilizar varios movimientos acrobáticos para que el jugador opuesto se relaje y afloje su guardia, quedando vulnerable para la aplicación de una técnica desequilibrante.

En general, el desarrollo de tal o cual estrategia se va produciendo tras jugar muchas veces en la roda, analizando los juegos realizados y observando el comportamiento de los compañeros de mayor experiencia.

\subsubsection{La musicalidad de la capoeira}

La música es característica de este arte, que proviene de la cultura afro en Brasil que determina la energía y el ritmo de la roda, entonces la música es un símbolo determinante de la capoeira: "Encuéntrese en la capoeira gran influencia del ritmo africano que está relacionado con la formación de la cultura afro-brasilera y con la identidad de su gente" (Silva, 2002, p. 77); no hay roda de capoeira sin instrumentos ni cantos. El primer juego de la roda comienza después de responder el primer coro: "no hay juego sin música... la música empieza antes del juego... cuando la música se detiene, el juego se detiene también" (Lewis, 1992, Cit. en De Oliveira \& Heine, 2010, p. 34).

La música en la capoeira cumple una función motivante de las acciones, marcando con su ritmo la cadencia y la velocidad de golpes y esquivas. La música, acompañada de las palmas en sintonía con los instrumentos, da una total armonía a la rueda de capoeira, donde son entonados varios cánticos que dan un carisma especial y típico que la capoeira ofrece por los movimientos ritmados marcados por los instrumentos.

\section{CAPOEIRA COMO HERRAMIENTA DE INTEGRACIÓN SOCIAL}

Las manifestaciones culturales de un grupo social, incluida la capoeira, se consideran de valor desde el momento en que son útiles a la sociedad. Del mismo modo, la capoeira con sus elementos tiene un valor único. A través de la práctica de la capoeira se adquieren y desarrollan aprendizajes y valores que contribuyen a la formación de cada uno como ciudadano.

Las principales características educativas de la Capoeira son la capacidad que tiene esta manifestación de trabajar valores humanos y permitir la inserción social de jóvenes excluidos y marginados. Además, la Capoeira es mucho más que un deporte. En Brasil es una forma de vida que desarrolla valores de solidaridad, compañerismo y respeto por los compañeros. La filosofía de la Capoeira es respetar al prójimo y a los más viejos, que poseen mayor grado de sabiduría (Mello, 2010, p. 300). 
Ya sea por sus orígenes históricos o fundamentos filosóficos, la capoeira es una herramienta que permite la inclusión social a través del trabajo educativo en valores humanos.

Para Da Silva (2007) existen tantas capoeiras como existen practicantes, es decir cada uno se desenvuelve como capoeirista de una manera particular y, al mismo tiempo, cada individuo desarrolla su capoeira de una manera única conforme su individualidad. Considerando a la roda de capoeira como un espacio de encuentro entre todas esas diferentes formas de capoeira, esta solo se hace posible si existe un diálogo pautado de respeto a las diferencias. Entonces, el respeto por la diversidad es un código implícito dentro de la capoeira.

La capoeira es un espacio diferente, a pesar de estar inserto en la sociedad, sus normas de conducta y tradición son bastantes diferentes. Es un lugar donde el capoeirista puede dejar todos los rótulos que le han sido impuestos y en condición de igualdad con sus camaradas para practicar capoeira (Da Silva, 2007, p. 19).

En las conclusiones de su trabajo de investigación acerca de la capoeira como vía de integración social de jóvenes vulnerables, Scarpetta (2012) define esta como con una experiencia exitosa de integración a la sociedad, la cual tiene en cuenta la generación de capital social colectivo e individual como alternativa de superación de la pobreza, ya que la capoeira, aunque no inserte a los jóvenes a la sociedad mediante ingresos económicos altos y definidos, sí incide para que estos salgan del barrio y adquieran una movilidad social y simbólica, pues permite que conozcan diferentes escenarios de la ciudad y del país, interactúen con personas que cuentan con diferentes niveles de capital social, económico y cultural a comparación de las personas que viven en el barrio y creen vínculos con otras instituciones educativas, escuelas, centros cívicos y culturales, aumentando su capital social, transformando su realidad y sus expectativas de vida.

\section{LA CAPOEIRA COMO COMPLEMENTO EN EL CURRÍCULO DE EDUCACIÓN FÍSICA}

La capoeira es una alternativa innovadora a considerar en el currículo de Educación física. Para incorporar la capoeira en la clase de Educación física, indiscutiblemente debemos profundizar en el currículo y en los aprendizajes esperados que se apropiarán a través de su práctica.

Su práctica viene creciendo cada vez más dentro de la escuela como contenido de la Educación física, por su eficacia en la estimulación de las percepciones básicas y el interés de los estudiantes, que tienen una influencia directa sobre el comportamiento afectivo y la creatividad (Barros et al., 2004).

La búsqueda de la implementación de nuevos contenidos como la capoeira, puede transformar los objetivos y la didáctica de enseñanza, las innovaciones en la planificación con otras áreas, puede proporcionar a los estudiantes nuevas experiencias a través de lo lúdico y se pueden tornar más participativos, integrados y consciente en el medio escolar (Barbosa \& Grajas, 2011).

Como anteriormente se ha mencionado, a pesar de que consideramos la capoeira como una disciplina en la cual podemos rescatar una amplia gama de aprendizajes esperados a bajar desde el currículo de Educación física, en este caso hemos seleccionado la creatividad 
y la expresión corporal por considerarlos dos aspectos fundamentales en el desarrollo de la confianza y autoestima de los estudiantes.

\subsection{CREATIVIDAD}

Cuando hablamos de creatividad se hace referencia a cualquier cosa que implique inteligencia, control y que entregue valor. La creatividad se aprende, al igual que todas las cosas que podamos aprender en la escuela, y se considera que el trabajo de expresión corporal y artística brinda un espacio fértil para el aprendizaje de la creatividad.

Es necesario que en nuestra sociedad existan entornos en los que cada uno pueda encontrar la inspiración necesaria para desarrollar su creatividad. Todos tenemos la capacidad de imaginar y crear, lo que pasa es que se tiene que desarrollar a través de entornos y herramientas que permitan la inspiración (Robinson, 2009).

La creatividad es un componente también de la evolución motricia humana; descubrir nuevos y diferentes hechos a través de la motricidad es algo que comienza con la exploración lúdica en la acción. Esto solo va a ocurrir en espacios en donde se presenten situaciones abiertas e interesantes para descubrir (Trigo, 2000).

La capoeira se puede utilizar para desarrollar la propia creatividad personal y profesional del profesor. De esta manera los alumnos se sentirán en confianza de liberar sus actos creativos, de no sentir vergüenza, de sentirse queridos y respetados por su grupo (Barberis, 2003).

El clima humanizado es fundamental para generar el desarrollo de la creatividad; si se tiene como base la confianza y amor en el grupo, el aprendizaje es alegre y más significativo. Esto, aunque no esté trazado como contenido en la educación, es vital para que el aprendizaje sea liberador, para que los estudiantes estudien con alegría, con pertenencia y significación personal. Se puede crear conocimiento a través del proceso de aprendizaje (Rogers \& Freiberg, 1996).

La capoeira es un juego de preguntas y respuestas. El jugador actúa según lo que hace el otro y es común que se encuentren en situaciones imprevistas, lo que hace que aparezcan nuevos movimientos. Para atrapar al compañero y no encontrarse atrapado, el practicante desarrolla la creatividad.

Es importante destacar que una característica propia de la capoeira es la posibilidad creativa de movimientos encadenados formados de secuencias de movimientos de gran variedad que, la mayoría del tiempo, son producto del dejarse llevar por la música y la improvisación (Barbosa, 2005).

La capoeira requiere mucha concentración, conexión de todos los sentidos y comunicación con el compañero. La improvisación y el sentido lúdico predominan en el juego que se manifiesta en crear movimientos y jugadas que logren engañar y hacer caer al otro. Encajar movimientos con el otro, ocupar los espacios vacíos, seguir el ritmo de la música, todo esto se trabaja a través de la creatividad.

\subsection{EXPRESIÓN CORPORAL}

Se plantea como expresión corporal expresarse libremente a través de vivenciar nuestra corporeidad (Trigo, 1999). De acuerdo con esta idea, Trigo define que toda actividad humana, todo movimiento que sea con sentido y significancia para el Ser, y en la cual se ponga de manifiesto la corporeidad del individuo, puede ser considerada como expresión corporal. 
En el ámbito de la Educación física, la expresión corporal debe contribuir al desarrollo integral del individuo, potenciando el conocimiento y desarrollo del lenguaje corporal a través de técnicas que favorezcan exteriorizar lo más interno y profundo de cada individuo a través del cuerpo en movimiento. Expresar sensaciones, emociones, sentimientos, ideas y pensamientos con el fin de comunicar; crear diálogos corporales, preguntas y respuestas, poner de manifiesto un mensaje (Ortiz, 2002).

La expresión corporal se basa en el desarrollo de los sentidos, la percepción y en la exploración de toda la complejidad motricia del ser humano. La comunicación y la creatividad están dentro de los objetivos desarrollados en su práctica (Botella, 2003), es decir, toda actividad en la cual el ser humano tenga implicancia: un partido de fútbol, una dramatización, recitar un poema, una carrera, una danza o un juego.

La capoeira entrega herramientas que facilitan el conocimiento propio de la corporalidad y la creación de formas de expresión. La justificación educativa de la capoeira incorpora un aspecto afectivo importante para el alumnado, que se basa en la noción de la posibilidad de la comunicación no verbal. A través del contacto corpóreo se transmite no solamente la fuerza y energía, sino componentes de tipo afectivo y emotivo. Todo ello permite enriquecer de forma global la construcción armoniosa de la formación del alumnado, pues es cierto la capoeira entendida de una forma "actual", alejada de la oposición, tiene un carácter cooperativo absoluto que resulta muy difícil de observar en cualquier otro deporte en el que exista adversario, especialmente, en los deportes de lucha.

\subsection{APRENDIZAJE DE VALORES SOCIALES A TRAVÉS DE LA CAPOEIRA: COOPERACIÓN}

Cuando dos personas juegan, realizan encajes de movimientos de ataques, defensas y contraataques que no permiten el conflicto. Tal característica demuestra la capacidad de promover actitudes pacíficas, el uso del diálogo y la negociación cuando se hace necesario resolver problemas. Elementos inherentes a la capoeira, como la estima que produce el desafío, la aceptación del resultado del juego como acto de cooperación, el desarrollo de la capacidad de análisis y de adaptación, hacen que la capoeira ayude decididamente a la construcción de la personalidad individual y social del alumnado.

En la práctica de la capoeira se permite la convivencia diversificada, ya que el alumno se relaciona con todos los del grupo, desarrollando de esa manera la capacidad de respetar las diferencias. Esta capacidad está relacionada con el pilar de aprender a convivir (Mello, 2010). A pesar de que su origen es la lucha y que contiene movimientos de ataque y defensa, se plantea que el contacto físico es innecesario, se evitan los golpes, y se pone de manifiesto el cuidado y el respeto por el otro. La importancia del cuidado de la integridad física y emocional de los compañeros; cada uno es importante e irremplazable en el grupo. Para dar mayor profundidad al valor educativo de la capoeira, vamos a bajar las competencias y objetivos del currículo para ser trabajados a partir de la práctica de esta disciplina.

\section{INTERVENCIÓN PRÁCTICA}

En el marco de los estudios de Máster en Actividad motriz y Educación, mención en Inclusión Social en la Universidad de Barcelona, el centro elegido fue una escuela pública de primaria, con una población con características de exclusión y riesgo social. 
La propuesta fue introducir en la clase de Educación física una unidad didáctica de capoeira que consistía en 8 sesiones, con una clase semanal. El tiempo de práctica fue un total de 100 horas, distribuidas en 12 horas semanales con 3 horas de permanencia diaria en la escuela de lunes a jueves.

Los cursos seleccionados para la intervención fueron $1^{\circ}$ a $6^{\circ}$, es decir el ciclo completo de primaria. La intervención práctica fue de 1 hora semanal por curso, con una matrícula de entre 17 a 25 niños y niñas por curso.

\subsection{CONTEXTO ESCOLAR}

En el centro, hasta la fecha de intervención práctica había 387 niños y niñas matriculados. Alrededor de un $45 \%$ de los alumnos son de origen extranjero. De estos, la mayoría son procedentes de Sudamérica, Pakistán y del Norte de África, y de manera más minoritaria de países de Europa del Este y China. También hay un porcentaje importante de Etnia Gitana con dos ramas diferenciadas: los autóctonos y los de procedencia Galaicoportuguesa.

El nivel socioeconómico y cultural de la mayoría de las familias es bajo o muy bajo; aunque se encuentra una pequeña parte con un nivel medio, este es cada vez menos significativo dentro de las familias de la Escuela.

Algunas de las familias se encuentran en una situación desfavorecida cercana a la marginación. Otros sufren una desestructuración importante, y cada vez más aumentan las familias monoparentales. Habría que destacar también una parte importante de alumnos con necesidades educativas especiales: la escuela tiene alumnos usuarios de silla de ruedas y otros que se desplazan con dificultad apoyados de muletas, también hay alumnos con síndrome de Down y trastornos del aprendizaje.

La escuela tiene un elevado índice de alumnos que no superan todas las áreas al acabar la educación primaria y, además, un factor que perjudica el aprendizaje de los estudiantes es un alto porcentaje inasistencia a clases.

\subsection{METODOLOGÍA DE ANÁLISIS DE SESIONES: DIARIO DE CLASES}

En el transcurso de cada sesión se siguió, a través de un cuaderno de registro, las impresiones la clase anécdotas, el resultado de las actividades, el logro de los objetivos y la participación de los alumnos.

También se elaboró un registro por parte de los alumnos en que respondían dos preguntas: ¿Qué aprendí hoy?, ¿Qué fue lo que más me agradó y lo me disgustó hacer en la clase?

En el análisis se han considerado los aspectos más significativos de las sesiones, así como también las actividades que no dieron resultado o que no se logró trabajar por distintos motivos. Para facilitar el análisis se consideró las sesiones por ciclo: primer ciclo $\left(1^{\circ}\right.$ y $\left.2^{\circ}\right)$, segundo ciclo $\left(3^{\circ}\right.$ y $\left.4^{\circ}\right)$ y tercer ciclo $\left(5^{\circ}\right.$ y $\left.6^{\circ}\right)$. Así cómo también a los alumnos que obtuvieron como mínimo un $85 \%$ de asistencia.

Por las características sociales de los alumnos de la escuela, es de gran relevancia en su formación el aprendizaje de actividad motriz, enfocada no solo al movimiento sino que al trabajo de auto-superación, autoconfianza, valores sociales, cooperativos e inclusivos, y en este caso las artes corporales trabajan en profundidad estas áreas. 
El aprendizaje de la creatividad y la expresión motriz generan herramientas importantes para la inclusión social, a través del juego cooperativo. No obstante, para que estos aprendizajes se logren se deben crear los espacios y las situaciones propicias. La propuesta de capoeira en la clase de educación física se planteó desde esa perspectiva: generar espacios y momentos para que los alumnos construyan su propio aprendizaje, respetando sus tiempos, procesos personales y grupales.

Considero que se cumplieron los objetivos planteados en la planificación de la unidad didáctica:

- Los alumnos conocieron y aprendieron capoeira a través del juego.

- Se mejoró la disposición a trabajar en grupo o parejas en la clase, aceptando y valorando a los compañeros.

- En los cursos de mayor edad se logró crear conciencia respecto a que si todos trabajan y si cada uno mejora y consigue pequeños logros, todo el grupo crece y también gana. El logro de uno es el ogro de todos, por lo cual cada uno merece aceptación y respeto.

- Valoración del trabajo de creación y expresión, los cuales fueron los momentos de mayor aprendizaje significativo en los alumnos.

Por parte de los alumnos, en el contexto de la clase mejoraron conductas negativas de relación, pienso que esto se generó principalmente por la metodología del juego, trabajo a base de valores, y principalmente la generación de actividades en que los alumnos debían crear y resolver tareas, eso los mantenía preocupados y concentrados en la actividad, no había tiempo para que se crearan espacios de conflictos.

Considero que la intervención práctica a través de la unidad didáctica de capoeira fue un éxito entre los niños y profesores de Educación física. El análisis de esta experiencia ha generado elementos para realizar una propuesta de innovación docente en el área de Educación física, que consiste en una propuesta de progresión metodológica de para el aprendizaje de capoeira de $1^{\circ}$ a $6^{\circ}$ grado.

\section{PROPUESTA DE INNOVACIÓN DOCENTE}

En el contexto de la práctica profesional de máster, se dio lugar a la implementación de una unidad didáctica de capoeira, situada en las clases de Educación física y dirigida para alumnos y alumnas de primer y tercer ciclo de la Escuela General Prim. Esta experiencia profesional ha generado elementos valiosos para elaborar un proyecto de innovación en el área de Educación física, específicamente en torno al desarrollo del bloque de actividad física artístico-expresiva para primero, segundo y tercer ciclo de primaria.

La progresión metodológica de capoeira para cada ciclo de primaria está diseñada en relación a los episodios de clases definidos y a las características de cómo aprenden los niños en las diferentes fases etarias.

\subsection{OBJETIVO}

Esta propuesta de innovación tiene por objetivo el desarrollo de una progresión metodológica del aprendizaje de capoeira, a partir de $1^{\circ}$ hasta $6^{\circ}$ grado, es decir cubrir los tres ciclos de la enseñanza en primaria. 


\subsection{JUSTIFICACIÓN}

- La importancia de incorporar en la clase de Educación física actividades motrices no tradicionales, en complemento al currículo. La capoeira es una disciplina muy atractiva para los alumnos y alumnas, ya que representa diferentes ámbitos y alternativas de aprendizajes. Al ser una actividad motriz multidisciplinar, abre nuevas posibilidades de proyectos de innovación docente transversal en diferentes asignaturas.

- La toma de conciencia de la inclusión social debe estar involucrada con el aprendizaje y los contenidos, es por esto que la metodología de capoeira se fundamenta a base del trabajo cooperativo y valores socio-educativos.

- Sacar ventaja de la cantidad de familias, hermanos y amigos del barrio que estudian en la escuela. El hecho de que los alumnos y alumnas aprendan capoeira al mismo tiempo, independiente del curso y grado, puede generar entre ellos experiencias motrices en común y el proceso se transforma en un aprendizaje más significativo al relacionar los vínculos familiares y sociales. Así como también que el aprendizaje de la capoeira se pueda transferir a su práctica fuera de la escuela.

\subsection{METODOLOGÍA}

La siguiente propuesta está pensada respetando las características fisiológicas, sicológicas, cognitivas y afectivas de los niños de 6 a 11 años. Las clases tipo tienen una duración de una hora (60 minutos).

La capoeira es un juego y, como tal, la forma de aprenderla debe responder a esta característica: entre más cercana a la realidad de juego sean las prácticas, mejor se aprenderá a dar respuestas creativas. Es aquí donde se da énfasis en que la gran parte de las actividades deben ser a base de juegos de cooperación, en los cuales se trabaje de forma transversal los valores y habilidades sociales.

Se deben aplicar metodologías y actividades que dejen libertad para la creación. El profesor propondrá temas generales que orientarán globalmente el trabajo y el alumnado plantea los problemas a resolver. Esto se justifica al aprender un arte donde la creatividad de cada uno se expresa en la combinación de los diferentes elementos de la técnica y la estrategia de juego.

\subsection{PROGRESIÓN DE APRENDIZAJE}

La clase se compone de episodios de diferente duración y objetivo, ajustándose estos a la respuesta que manifiesten los alumnos y a la etapa de aprendizaje en que se encuentren. El rol del profesor en esta propuesta necesita su integración y participación en los juegos y actividades, animando y ejemplificando los modelos a aprender.

A continuación se describen las etapas, que se utilizan para organizar las clases de capoeira, la forma recomendada para su aplicación y su progresión en el tiempo:

\section{Introducción y motivación}

Corresponde a realizar una breve introducción acerca de los objetivos de la sesión y lo que se espera de ellos en cuanto a comportamiento y atención. Luego se pasa a las actividades de calentamiento que consistirán, preferentemente, en juegos y expresión que impliquen concentración y movimiento. 


\section{Familiarización}

El objetivo es que los alumnos exploren a través del juego la motricidad característica de la capoeira y facilitar el aprendizaje posterior de los diferentes elementos técnicos. Para ello utilizaremos actividades que exijan desplazarse en cuadrúpeda, imitar a animales y representar roles.

\section{Aprendizaje de movimientos y figuras básicas}

El objetivo es el que los alumnos aprendan los elementos del juego de capoeira. Para ello se requiere el trabajo en parejas, ejecutando uno el ataque y el otro la defensa, realizando así un diálogo y disfrazando la lucha en danza.

\section{Música y ritmo}

El objetivo es que los alumnos aprendan a cantar y tocar los instrumentos. Se necesitará el apoyo de cancioneros e instrumentos suficientes para el grupo. Se recomienda fabricación de instrumentos con material reciclado.

\section{Roda de capoeira}

En la roda los alumnos ponen de manifiesto lo aprendido y se enfrentan ante situaciones inesperadas nacidas del juego mismo. En esta instancia el profesor puede apreciar claramente si los alumnos son capaces de ejecutar más o menos correctamente los diferentes gestos técnicos y su aplicación táctica, como también si son capaces de mantener el entusiasmo de la roda a través de los cantos y palmas animadas.

El profesor debe procurar en todo momento que los alumnos roten en los roles de jugador, músico y cantador para que aquellos que presentan un desenvolvimiento mayor en un área no queden estancados y se abran a las otras áreas que no dominan o que presentan para ello un cierto grado de dificultad. De esta manera, se garantiza la participación de todos.

\section{Vuelta a la calma y retroalimentación}

Volver a la calma a los alumnos y evaluar la clase. Es el momento indicado para que el profesor recapitule los movimientos aprendidos y conduzca a los alumnos a la reflexión acerca de su aprendizaje. Se pueden hacer preguntas tales como ¿qué aprendimos el día de hoy?, ¿qué fue lo que más le gusto?, ¿cuáles son los beneficios en las actividades realizadas? Se puede incluir en esta parte el compartir alimentos como frutas u otros saludables.

\section{CONCLUSIONES}

Otorgo gran importancia al aprendizaje de la capoeira a nivel escolar y al conocimiento de las experiencias de otros profesionales de la capoeira, que buscan realizar un trabajo enfocado a una práctica integral y social, por encima del aspecto de la técnica y lucha. 
En relación al primer objetivo planteado: analizar la capoeira como herramienta de inclusión social, esto se realizó a través de la revisión bibliográfica de diferentes autores que hacen referencia a proyectos sociales de capoeira y a las artes corporales para el cambio social. Este análisis da cuenta de que se otorga a la capoeira un rol protagónico en proyectos sociales no solo en Brasil, sino que en diversos países de Latinoamérica y el resto del mundo en donde puedan existir situaciones de pobreza y exclusión social.

De esta forma, la Capoeira se considera como un instrumento motor para la ciudadanía, y es a su vez una disciplina de expresión motriz que en su práctica promueve la conciencia social, los valores humanos, la inclusión y la cooperación. Especialmente, la capoeira toma fuerza entre sectores más desfavorecidos, con mayor pobreza y discriminación social.

El segundo objetivo de este trabajo consistió en ubicar la Capoeira como contenido del currículo de Educación física. Esto nace de la necesidad de incluirla dentro del contexto educativo formal de una institución educativa, que en este caso fue la escuela. Para esto se estudió el currículo de Educación física en España y se logró incluir la capoeira en el bloque de contenido número 3: Actividad Física Artístico-Expresivas. Esto, a su vez, se profundizó en los objetivos de desarrollo de la creatividad y expresión corporal, porque se consideró que el aprendizaje de estas capacidades desencadena una serie de cambios en los estudiantes en cuanto a la auto imagen, autoestima y confianza; que son los cambios de conciencia fundamentales que se pretenden lograr en las personas a través de las artes corporales para el cambio social.

De todas maneras, esta categorización de la capoeira dentro del currículo de Educación física puede ser incorporada también a otros bloques de contenidos, ya que la capoeira es una disciplina en la cual se pueden trabajar varios aspectos del aprendizaje motor y de la formación personal que se incluye en los objetivos del currículo. Esto deja de manifiesto el valor educativo que presenta la capoeira, a través del desarrollo de capacidades importantes para la formación educativa en los alumnos y alumnas y de la forma en que contribuye en el aprendizaje a edad escolar en el logro de los objetivos propuestos para el área de Educación física en el ciclo de primaria.

Para el tercer objetivo se llevó a cabo en la práctica profesional del máster la aplicación de la programación de una unidad didáctica de capoeira en la Escuela General Prim, esto a modo de intervención social e innovación educativa en la asignatura de Educación física, la cual se desarrolló en el primer y tercer ciclo de primaria. Desde esta experiencia profesional se observaron las diferentes formas en que ocurre el aprendizaje motriz y social de la capoeira con respecto a la edad de los alumnos y alumnas. Se analizaron las actividades que dieron buen resultado, así como también las actividades que fracasaron en cada clase y grupo.

La aceptación, participación y valoración de la actividad por parte de los alumnos fue muy positiva. Los estudiantes se involucraron con la actividad, aprendieron qué es capoeira y en qué consiste su juego, esto quedó de manifiesto en la evaluación formativa de cada clase y en la evaluación de proceso final cuando todos los alumnos participantes realizaron una roda de capoeira en donde aplicaron sus nuevos conocimientos y creaciones en duplas. Cabe destacar que los estudiantes manifestaron un alto grado de comprensión de la capoeira a través de la música y los juegos. Por otro lado, la actividad fue bien aceptada y valorada por los profesores de Educación física, por los profesores tutores de cada curso y por la dirección, ya que ellos también observaron el interés que demostraban los estudiantes por las clases de capoeira. 
Desde este hecho se puede concluir que en el contexto de la práctica pedagógica, y específicamente en relación al aprendizaje de la capoeira en escuelas de sectores vulnerables y en riesgo social, este arte se destaca como un medio educativo para la formación de los estudiantes. En este contexto educativo, enseñar es un doble desafío por la situación social de los alumnos, en que no todas las actividades son bien aceptadas, en general existe desconfianza y falta de compromiso por parte de los estudiantes, es por esto que se hace necesario presentar actividades motrices no tradicionales e innovadoras que llamen la atención a los estudiantes para que sientan la necesidad de participar y aprender.

El cuarto y último objetivo de este trabajo se concretiza a partir de la intervención práctica en la escuela, con la implementación de la unidad didáctica de capoeira y su correspondiente evaluación del proceso de aprendizaje en los estudiantes. Se estructuró una propuesta de innovación docente que consiste en una secuencia de progresión metodológica desde primer ciclo hasta tercer ciclo de primaria, es decir desde $1^{\circ}$ a $6^{\circ}$ grado. Este hecho contribuye a que la capoeira pueda ser enseñada y aprendida a través del bloque de actividad motriz de expresión artística a todos los cursos desde primero a sexto a la vez. Bajo esta consideración se concluye que la capoeira es un recurso de innovación y que puede ser usado como herramienta de inclusión social en las escuelas que se ubican en barrios de exclusión social y marginalidad.

El presente trabajo ha contribuido a conocer las experiencias de la capoeira en las clases de Educación física, lo cual hace afirmar que es un complemento concreto, real e innovador para la escuela. También ha servido para aclarar el enfoque curricular en el cual se puede incluir la capoeira y cómo bajarlo a la planificación de una unidad didáctica a través de diversos juegos y actividades. Como consecuencia de esto surge la necesidad de que también a nivel de formación universitaria la capoeira sea considerada dentro del currículo del profesor de Educación física, de lo cual ya se conocen algunas experiencias en universidades de Brasil.

Si bien es cierto la capoeira ha traspasado fronteras, culturas, idiomas y hoy en día es practicada en más de 120 países en todo el mundo, no he encontrado referencias bibliográficas que den cuenta de la capoeira como contenido del currículo de Educación física fuera de Brasil. Es muy interesante conocer a través de diversos artículos que cuentan experiencias de la capoeira como una actividad multidisciplinar que se puede trabajar como contenido en las escuelas en asignaturas como música, arte, historia, literatura, educación física e incluso matemática.

Es por esto que quiero dejar abierta la posibilidad de ampliar la propuesta de innovación educativa de capoeira no solo dirigida a la asignatura de Educación física, lo cual sería mucho más interesante y constructivo si se lograra hacer trabajar a varias asignaturas para un mismo contenido. La riqueza cultural, social y artística que contiene la capoeira en sí misma, y desde una mirada multidisciplinar, pueden dar espacios para descubrir talentos, desarrollar habilidades sociales y mejorar la autoimagen y relación con el entorno.

En una propuesta de inclusión social y en valores educativos a través de la capoeira, teóricamente los resultados de una intervención social en búsqueda de la integración y emancipación de los alumnos debieran ser exitosos. Sin embargo, en mi experiencia personal debo dar cuenta de que esto no siempre sucede, ya que si la práctica de la capoeira no está bien orientada, planificada y adecuada a las necesidades del grupo de alumnos, no solo fracasa la clase o la actividad, sino que no se rescata el valor social y educativo de la capoeira y, finalmente, no se logra la inclusión a través de esta. 
Es por esto que surge la profunda necesidad de mejorar las prácticas pedagógicas, para entregar y transmitir todos los beneficios que la capoeira pueda tener para promover la inclusión social. La capoeira es una estrategia de cambio social que, a través de la acción motriz, busca la transformación de actitudes.

Los profesores de Educación física debemos considerar otras actividades catalogadas como no tradicionales para ampliar la diversidad de disciplinas y de aprendizajes en nuestros estudiantes. Así como también acercar la cultura corporal popular a la escuela para motivar y darle significancia a la asignatura que muchas veces se aleja de los intereses y necesidades de los alumnos.

La capoeira tiene un fuerte componente de trabajo de expresión corporal y de desarrollo de la creatividad por su potente trabajo rítmico y musical. Estos contenidos se han considerado en este trabajo por ser factores importantes de autoconocimiento y de descubrimiento de la propia corporalidad y su relación con el entorno en los estudiantes.

Sin embargo, por originarse una lucha, se recomienda trabajar las actividades de la capoeira con un enfoque cooperativo, con valores educativos por la paz y la no violencia. Cabe señalar que la capoeira es una disciplina sumamente inclusiva y que permite espacios para la participación de todos los estudiantes. Esto en sí es un valor intrínseco agregado de la capoeira por sus orígenes y filosofía, no obstante, ello no se va a generar por arte de magia; es vital la adecuada orientación del profesor y una clara propuesta de objetivos a trabajar.

Considerando la flexibilidad que presenta el currículo de Educación física, tanto en Chile como en España, la capoeira es una propuesta innovadora posible de utilizar en las escuelas, y que no requiere estar explícitamente incluida en el currículo del Ministerio de educación, sino que más bien dependerá de la creatividad e innovación de los profesionales del área. También es una forma de difundir la capoeira y de plantear la posibilidad de que si el estudiante se interesa por esta disciplina la practique con más profundidad en una escuela de capoeira.

\section{REFERENCIAS BIBIOGRÁFICAS}

Barberis, S. (2003). La Capoeira. Posibilidades didácticas para la educación física y la expresión corporal. En G. Sánchez, B. Tabernero, F. Coterón, C. Llanos, \& B Learreta, Expresión, Creatividad y Movimiento (pp. 213-218). Salamanca: Amaru.

Barbosa, P. (2005). A capoeira no contexto da escola e da educação física. Monografía de máster, Universidade Regional do Noroeste do Estado do Rio Grande do Sul. Ijuí.

Barbosa, E., \& Grajas, M. (2011, Muy 10). A inserção da capoeira no currículo escolar. Efdeportes, 156 (156). Recuperado desde http://www.efdeportes.com/efd156/a-insercao-dacapoeira-no-curriculo-escolar.htm

Barros, A., Iório, L., \& Venancio, L. (2004). A sistematizaçao dos conteúdos da educação física escolar relacionada a os temas jogos e brincadeiras e capoeira, na perspectiva de docentes do ensino superior. Anais VIII Encontro Fluminense de Educação Física Escolar (Ed.), VIII Encontro Fluminense de Educação Física Escolar (p. 5). Niterói: Universidade do Rio Claro.

Botella, A. (2003). Música y Expresión Corporal al servicio de la Educación. En G. Sánchez, B. Tabernero, F. Coterón, C. Llanos, \& B Learreta, Expresión, Creatividad y Movimiento (pp. 538-542). Salamanca: Amarú.

Da Silva, G. (2007). Sobre posibilidades de ejercicio da ética inter-humano no Jogo da capoeira. 
Revista Virtual de Gestao de Iniciativas Sociais, 10, 9-19. Recuperado desde http://www.ltds.ufrj.br/ gis/anteriores.htm

De Oliveira, G., \& Heine, V. (2008). Capoeira, un instrumento psicomotor para a ciudadanía. Sao Paulo: Phorte.

Grasso, A. (2006). La Corporeidad: hacia una inteligencia corporal en la escuela. M. Castañer (Ed.), Inteligencia Corporal en la escuela (pp. 9-31). Barcelona: GRAÓ.

Gonçalves, L., Correa, D., Da Silva, C., Alves, S., \& Toro, S. (2012). Etnomotricidad: Juegos de resistencia cultural en la comunidad Caizara de Ilhabela-Brasil. Revista de Estudios Pedagógicos, Número especial XXXVIII, 249-266.

Hérnandez, J. (2008). De cómo separar los elementos de la lógica interna y de la lógica externa. Acción Motriz: Revista Científica Digital, 1(1), 5-9. Recuperado desde http://www.accionmotriz. com/revistas/1/1_1.pdf

Mateu, M., \& Torrents, C. (2012). Lógica interna de las actividades físicas artístico-expresivas. Tándem Didáctica de La Educación Física, 39, 48-61.

Mello, K. (2010). Origen y Evolución de la Capoeira: Valor socioeducativo de su práctica en la actualidad. Tesis doctoral, Universidad de León. León.

Olaechea, C., \& Georg, E. (2007). Arte y transformación social; Saberes y prácticas de crear vale la pena. Buenos Aires: CVLP.

Ortiz, M. (2002). Expresión corporal. Granada: Grupo Editorial Universitario.

Parlebas, P. (2001). Juego, deporte y sociedad: Léxico de praxiología motriz. Barcelona: Paidotribo.

Robinson, K. (2009). El Elemento: Descubrir tu pasión todo lo cambia. Barcelona: Grijalbo.

Rogers, C., \& Freiberg, J. (1996). Libertad y Creatividad en la Educación (3 ${ }^{\text {ra }}$ ed.). Barcelona: Paidos Educador.

Scarpetta, A. (2012). La capoeira como una vía de integración social de jóvenes vulnerables. Disertación de master. Universidad Colegio Mayor de Nuestra Señora del Rosario, Bogotá.

Sergio, M. (1996). Epistemología da Motricidade Humana. Lisboa: FHM. Universidad técnica de Lisboa.

Silva, L. (2002). Capoeira: uma expressão antropológica da cultura brasileira. Paraná, Brasil: Massoni.

Tavares, L. C. (2006). O corpo que ginga, joga e luta: A corporeidade na capoeira. Salvador: L. C. Tavares.

Trigo, E., Álvarez, M., Aragunde, J., García, J., Graña, I., Fernández, G., Maestu, J., Pazos, J., Rey, A., Rey, C., Sánchez., M.(1999). Creatividad y Motricidad. Barcelona: INDE.

Trigo, E. (Coord.). (2000). Fundamentos de la Motricidad: Aspectos teóricos, prácticos y didácticos. Madrid: GYMNOS.

Zubiri, X. (1986). Sobre el hombre. Madrid: Alianza. 